\title{
Understanding the Factors that Influence the Primary Appraisal of mHealth Tools in Developing Countries: An Exploratory Case-Study in Nigeria
}

\author{
Emmanuel Eze \\ Department of Business Information Systems, \\ University College Cork, \\ Cork, Ireland \\ emmanuel.eze@ucc.ie
}

Rob Gleasure

University College Cork,

Cork, Ireland

Ciara Heavin

University College Cork,

Cork, Ireland

\section{Abstract}

Shortages of health workers, infrastructural deficiencies, limited access to medical care are just a few of the many barriers to care in developing countries. The integration of smartphones and mobile devices into healthcare systems has been proposed to address some of the physical barriers to care and service delivery. These mHealth solutions extend the reach of medical care into rural areas of developing countries. However, it is not clear how mHealth solutions designed and tested in one developing region can be positively appraised for use in others. This study frames this problem using a coping theory approach based on an exploratory casestudy to understand the factors that influence primary appraisal of smartphone-enabled clinical guidelines (mHealth tool) for accessing, classifying and eliciting treatment recommendation for sick children under the age of five by rural healthcare workers (RHCWs). Findings identified a set of factors which are bound as an emerging explanatory positivity model that influence primary appraisal of an mHealth tool in a new context. These factors are the set of individual and social factors that governments, funding bodies and nongovernmental organisations should consider before embarking on the introduction of an mHealth tool in rural communities of developing countries. It is envisaged that by understanding the factors that influence primary appraisal, that is, either as an opportunity or a threat, practitioners and organisations will support positive appraisal and minimise the occurrence of negative ones when introducing mHealth tools. These findings have implications for theory, practice, and future research as explained in the concluding section of this paper.

Keywords: Healthcare; Developing Countries; Mobile Technology; Coping Theory; mHealth; Rural Healthcare Workers.

\section{Introduction}

The ubiquitous nature of mobile information technology (IT) presents an opportunity to stimulate developmental activities in rural areas of developing countries (Datta, Byrd, Okoli, \& Mbarika, 2005; Furuholt \& Matotay, 2011). Mobile devices have the potential to overcome 
some of the physical challenges and infrastructural deficiency that hold back these areas (Aker \& Mbiti, 2010; Lee, Levendis, \& Gutierrez, 2012). This is due in part to the unique mobility and smaller infrastructural requirements when compared to landlines (Aker \& Mbiti, 2010; Lee et al., 2012). The developmental paradigm surrounding mobile phones has shifted from one that simply reduces communication and coordination costs to one that could transform lives through transformative applications of mobile services (Aker \& Mbiti, 2010; Kahn, Yang, \& Kahn, 2010). One example is the integration of smartphones and mobile devices into healthcare systems to address some of the challenges to care and service delivery in rural areas of developing countries (Donner \& Mechael, 2012; Free et al., 2013). The strategies of incorporating mobile technologies in healthcare services are collectively known as mobile health (mHealth) (Donner \& Mechael, 2012; Kahn et al., 2010).

The use of mHealth tools can vary in focus (Eze, Gleasure, \& Heavin, 2016b, 2018). First, mPrevention/Education tools provide preventive, advisory, counselling, and educational services (e.g. Hacking et al., 2016; Nhavoto, Grönlund, \& Klein, 2017). Second, mDataCollection tools are used to collect data that may inform other aspects of healthcare delivery (e.g Kabuya, Wright, Odama, \& O'Mahoney, 2014; Simon \& Seldon, 2012). Third, mDiagnosis applications are used to support the diagnosis of particular conditions (e.g. Chib \& Chen, 2011; Mavhu et al., 2017). Fourth, mTreatment apps are used to guide remedial healthcare interventions for specific patients (e.g. Alam, Khanam, \& Khan, 2010; Hufnagel, 2012).

The potential of these mHealth tools to navigate some of the barriers to medical care in developing countries has prompted a number of initiatives by governments, nongovernmental (NGOs), and research organisations to invest in innovative mHealth approaches to healthcare delivery. However, research has shown that most of these initiatives have struggled with deployment, particularly during the progression from pilot stages to large-scale nation-wide roll-out (Chib, van Velthoven, \& Car, 2015; Heeks, 2006). Although many scholars have used various models, e.g., Venkatesh, Morris, Davis, and Davis (2003); Taylor and Todd (1995), and Rogers (2003) to understand users' adoption processes but a few have examined users' appraisal process before adoption or use. It is argued that understanding an individual's cognitive appraisal process which provides information about the individual's behaviours or emotions would help a researcher understand the individual's disposition (Hareli \& Hess, 2010). This implies, that individual's behaviours or emotions influence individual's appraisal processes towards, for example, an IT occurrence in their environment (e.g. Beaudry \& Pinsonneault, 2005; Wisniewski, Xu, \& Chen, 2014). In a health context, scholars posit that a coping theory/framework can be effectively employed in the intervention, assessment or evaluation of an individual's psychological stress and coping responses (Fadel \& Brown, 2010; Lyon, 2000). This study uses coping theory to explore perceptions around new mHealth initiatives, with particular attention to perceived threats and opportunities as appraisal outcomes. More specifically, we ask what are the factors that influence the primary appraisal of an mHealth tool in a developing country?

The rest of the paper is outlined as follows. Section 2 discusses the theoretical background of coping and appraisal as it applies to mHealth in developing countries. Section 3 describes an exploratory case-study approach based on the potential introduction of a new mHealth tool for assisting the treatment of sick children under the age of five in Nigeria. Section 4 presents the findings of the study, which are bound as an emerging explanatory model for the primary 
appraisal of mHealth tools in developing countries. Sections 5 and 6 discuss the findings in relation to existing studies and presents a summary and conclusions.

\section{Primary Appraisal and Coping with new Technologies}

To understand primary appraisal and coping we turn to the theory by Lazarus and Folkman (1984) on Stress, Appraisal and Coping from the social psychology literature. Coping in Information Systems (IS) research is conceptualised as adaptation strategies, and this allows us to understand the individuals' behaviours that occur before, during, and after the implementation of a new technology (Beaudry \& Pinsonneault, 2005), such as mHealth tool. Lazarus and Folkman (1984) assert that individuals employ two-way processes to cope with a disruptive new IT occurrence, i.e., Appraisal and Coping.

\subsection{Coping Theory}

Coping theory is used to explore and understand the underlying relationships on how individuals respond to an IT occurrence in their environment (Beaudry \& Pinsonneault, 2005; Bhattacherjee, Davis, Connolly, \& Hikmet, 2017). Coping is defined as the "cognitive and behavioural efforts to manage specific external and/or internal demands that are appraised as taxing or exceeding the resource of the person [individual]" (Lazarus \& Folkman, 1984, p. 141). 'Internal' demands are personal needs or requirements such as the desire to excel, perform or execute, and 'external' demands refer to those activities impacted or influenced by the external environment (Beaudry \& Pinsonneault, 2005; Bhattacherjee et al., 2017). Coping is a significant concept in IS for theory and research on IT adaptation (Claggett, 2010; Fadel \& Brown, 2010). Coping theory explains the processes by which individuals frame and respond to disruptive events in their environment/workplace, such as a new IT occurrence (Beaudry \& Pinsonneault, 2005; Wisniewski et al., 2014).

IS scholars have applied coping theory in organisational settings to understand the individual cognitive responses to new IT in a work environment, three examples include: 1) In the context of an IT adaptation in a banking setting, Beaudry and Pinsonneault (2005), by building on the works of Lazarus and Folkman (1984) offered us an integrated model for understanding users' adaptation to an IT occurrence in a workplace, known as Coping Model of User Adaptation (CMUA). In applying coping in IT banking settings, CMUA adopts a process-oriented approach to coping and outlined four adaptation responses (Beaudry \& Pinsonneault, 2005). 2) In the context of an IT avoidance in a security oriented setting, Liang and Xue (2009) used coping in conjunction with cybernetics to present us with an integrated processes theory of coping and variance theory known simply as the Technology Threat Avoidance Theory (TTAT). By applying coping and variance theories in IT business settings, TTAT adopts a process-oriented approach to coping and variance theories to explain the individual IT user's behaviour of avoiding 'threat' of malicious information technologies (Liang \& Xue, 2009). 3) In the context of an IT appraisal and coping in a healthcare setting, Fadel and Brown (2010), utilised the CMUA model in a developed country environment to set the first step toward integrating theories of IS 'adoption and use' with coping theory by examining how adoptionrelated IS perceptions influence individual-level post-adoptive IS appraisal. These studies underline the significance of the application of coping processes in IS research to understand individuals' cognitive responses to the introduction of new IT in a work environment. 


\subsection{Appraisal}

Appraisal is defined as the cognitive evaluation and classification of an IT encounter in its various aspects with respect to the individual's well-being (Beaudry \& Pinsonneault, 2005; Lazarus \& Folkman, 1984). Appraisal processes are mediated by the individual's reactions and in every situation each individual appraises differently (Beaudry \& Pinsonneault, 2005; Lazarus \& Folkman, 1987). In CMUA model, two types of appraisals of interest are identified in the study of coping process, namely, 1.) primary and 2.) secondary appraisal processes (Beaudry \& Pinsonneault, 2005). It is argued that these two processes interact and may occur simultaneously (Christophe Elie-Dit-Cosaque \& Straub, 2011).

The process of 'primary appraisal' describes where individuals evaluate the importance of an event as a consequence of their situations and interests (Beaudry \& Pinsonneault, 2005; Folkman, Lazarus, Gruen, \& DeLongis, 1986). The outcome of such an evaluation is usually as either an opportunity or threat (Beaudry \& Pinsonneault, 2005; Christophe Elie-Dit-Cosaque \& Straub, 2011). For example, when a change occurs in an individual's workplace (e.g., introduction of an mHealth tool), the individual asks himself/herself, "What is at stake for me in this situation" (Beaudry \& Pinsonneault, 2005, p. 495). The four outlined adaptation strategies in CMUA model (Beaudry \& Pinsonneault, 2005) are: 1) Benefit maximising - when the new IT occurrence is perceived as an 'opportunity' and individuals feel they have 'high level' of control; 2) Benefit satisficing - when the new IT occurrence is appraised as an 'opportunity' but with a 'low level' of control; 3) Disturbance handling - when the new IT occurrence is perceived as a 'threat' and individuals feel they have a 'high level' of control, and 4) Self-preservation strategies - when the new IT occurrence is perceived as a 'threat' but with a low level of control. Individuals undertake the assessment of how much control they have over the new event and the opportunities or the threats it presents them in respect to their environment, and resources provided by their management (Beaudry \& Pinsonneault, 2005; Nach \& Lejeune, 2010). Individuals have high levels of control when they believe they have control over the event. High control users engage in 'problem-focused coping', for example, by expressing self-confidence in the ability to adapt themselves to the new environment or being able to manipulate features and functionality of the new (mHealth) IT (Beaudry \& Pinsonneault, 2005; Christophe Elie-Dit-Cosaque \& Straub, 2011). Individuals have low levels of control when they believe they have insufficient control over the event, thus engaging in 'emotion-focused' coping in which they believe there is little or nothing they can do about this change (Beaudry \& Pinsonneault, 2005; Nach \& Lejeune, 2010).

However, how people positively cope in the context of mHealth in developing countries remains unclear. Against this background we offer a new context on how to understand the 'positivity' of primary appraisal, namely, primary appraisal of an mHealth tool. This study applies the coping process to understand the positive actions or activities that would influence the assimilation of an mHealth tool in the rural communities of developing countries. The next section discusses the positivity of primary appraisal.

\subsection{Positivity of Primary Appraisal}

Positivity of primary appraisal describes an individual's tendency to have a positive or optimistic attitude towards some new IT in their work-environment. Positivity describes a summative judgement of the extent to which positive (desirable) outcomes overcome negative (undesirable) outcomes (Beaudry \& Pinsonneault, 2005; Lazarus \& Folkman, 1984). Positive and negative outcomes in a primary appraisal process are regarded as 'opportunities' or 
'threats' respectively (Claggett, 2010; Christophe Elie-Dit-Cosaque \& Straub, 2011). 'Opportunity' refers to a situation that has been assessed as having 'positive outcomes' for the individual, invoking emotions of excitement and anticipation (Bhattacherjee et al., 2017; Claggett, 2010). For example, a 'strong task-technology fit' (Goodhue \& Thompson, 1995) could be considered by a user as an opportunity to improve his/her performance in a workplace (Beaudry \& Pinsonneault, 2005; Fadel \& Brown, 2010). 'Threat' refers to the individual's feeling or belief that the change may negatively affect him/her. This negative feeling could be referred to a situation where a loss (e.g., loss of power or position) or harm is anticipated and could be categorised by emotions of anger, fear or anxiety (Bhattacherjee et al., 2017; Wisniewski et al., 2014). To promote goal-oriented work attitudes and behaviours, organisations' actions must support those factors that foster positivity (Avey, Luthans, \& Youssef, 2010).

A number of factors could impact the positivity of primary appraisal for a new mHealth tool. Researchers have stressed the need to attend to social, cultural, and contextual factors of stresscoping (e.g. Aldwin, 2007; Chun, Moos, \& Cronkite, 2006). Social and cultural variations significantly influence the degree of positivity of primary appraisal for a stressful IT (e.g. mHealth tool) occurrence (Kuo, 2011; Newton \& McIntosh, 2010). Following the transactional nature of Lazarus and Folkman (1984) coping theory, these factors, i.e., 'individual' and the 'social' (environment) are viewed as being in a dynamic and mutual relationship (Christophe Elie-Dit-Cosaque \& Pallud, 2010; Christophe Elie-Dit-Cosaque \& Straub, 2011).

Individual factors are internal behavioural or emotional factors affecting how the individual appraises a particular context or situation (Beaudry \& Pinsonneault, 2005; Bhattacherjee et al., 2017). For example, research has shown that an individual's previous experience with technology has an impact on the way they perceive new technology in their environment (Hackbarth, Grover, \& Mun, 2003; Venkatesh \& Morris, 2000). Specifically, innovative individuals have been found to be positively predisposed to IT in their work environment (Lee, Qu, \& Kim, 2007; Lewis, Agarwal, \& Sambamurthy, 2003). That is, individuals' cognitive processes underline the basic tenants of an individual's reaction to a stressful event (e.g. new IT) (Krohne, 2002; Miller \& Kaiser, 2001). This is especially true for the following reasons: first, individuals' 'cognitive skills' mediate the type of reaction they have towards an IT occurrence in their workplace (Beaudry \& Pinsonneault, 2005; Fadel \& Brown, 2010); second, 'cognitive appraisal styles' significantly impact on how individuals appraise and adapt to stressful situations (Christophe Elie-Dit-Cosaque \& Straub, 2011). Thus:

Proposition 1 (P1). Individual factors influence the positivity of the individual's primary appraisal of an mHealth tool in developing countries.

Social factors are conceptualised in this paper as external factors that are outside the control of the user (or exceeding the resource of the person). Social factors are situationally, contextually or environmentally dependent (Beaudry \& Pinsonneault, 2005; Mathieson, 1991). IS scholars posit that 'social factors' influence individual's primary appraisal (Bhattacherjee et al., 2017; Christophe Elie-Dit-Cosaque, Pallud, \& Kalika, 2011). 'Social factors' include for example, organisational mechanisms (e.g. training and resource support), peers support (e.g., from coworker, family and friends) and environmental conditions (e.g. culture and working conditions) (Johnston, Warkentin, McBride, \& Carter, 2016; Terry, 1994). Findings show that social factors may deny an individual the opportunity to use IT even when the individual feels 
he/she could benefit from doing so (Claggett, 2010; Ragu-Nathan, Tarafdar, Ragu-Nathan, \& $\mathrm{Tu}, 2008)$, for example, network coverage (e.g. Stanton et al., 2015). Thus:

Proposition 2 (P2). Social factors influence the positivity of an individual's primary appraisal of an $m$ Health tool in developing countries.

This allows a preliminary model to be developed representing high-level constructs that require deeper exploratory propositions (Figure 1).

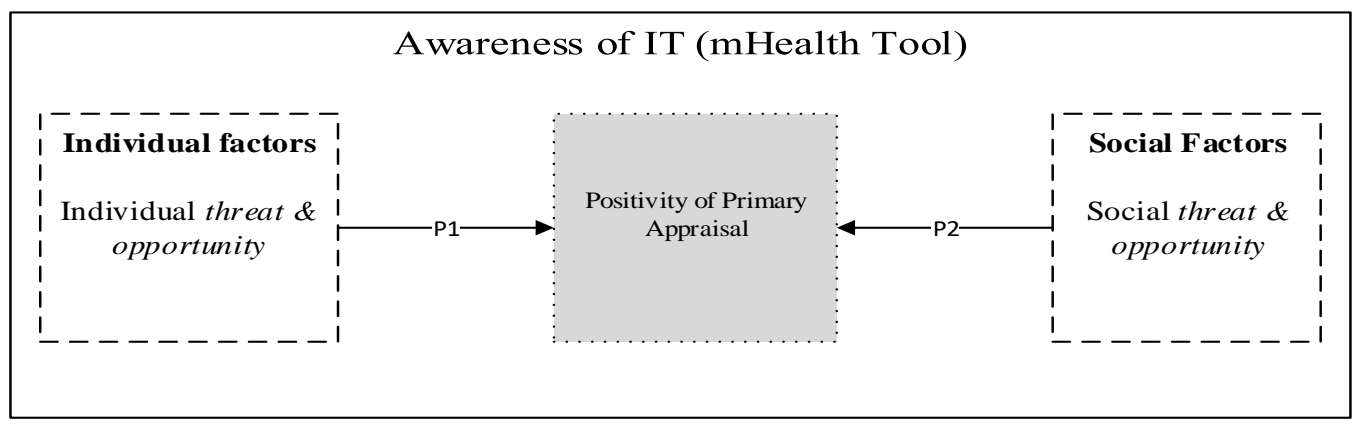

Figure 1: Preliminary/Sensitising Research Model

\section{Method}

\subsection{Research Methodology and Site Selection}

The study adopts an exploratory case-study approach (Yin, 2013) aimed to understand the primary appraisal processes that influence the assimilation of an mHealth technology for use in new areas of developing countries. The area selected for study was the Nsukka Local Government Area in Enugu State, in the South Eastern Region of Nigeria. This area was selected for two main reasons: (i) Poverty has historically been high, meaning infrastructural and cultural challenges are significant (ii) One of the researchers is from the area, meaning phenomena could be studied with a high degree of access and immersion. These qualities accommodate a case-study; an approach suitable to explore domains that maybe too complex for other research methods (e.g., surveys or experimental) (Jensen \& Vatrapu, 2015; Sarker, Sarker, Sahaym, \& Bjørn-Andersen, 2012).

This investigation focused on the primary appraisal of an mHealth tool that was designed and developed for a country in East Africa. The mHealth tool is underpinned by the WHO and UNICEF's integrated Community Case Management (iCCM) guidelines ${ }^{1}$. iCCM are a briefer version of the Integrated Management of Childhood Illness (IMCI) guidelines aimed at reducing child mortality. iCCM guidelines are region specific, they are used by healthcare workers in rural communities to assess, classify and treat children between the age of 2 months and five years for illnesses such as malaria, cholera and diarrhoea. The mHealth tool digitalises the existing paper-based iCCM clinical guidelines decision support rule engine by defining the classification and treatment rules in Extensible Mark-up Language (XML).

\subsection{Data Collection and Sampling}

A purposeful sampling approach (Patton, 1990) was used to promote the selection of 'information rich' sources for this study (Ram \& Khatri, 2005). Following Knoke (1994), interviewees/stakeholders were selected based on reputational and positional methods in the

${ }^{1}$ For more details, please see the UNICEF website at https://www.unicef.org/ 
target communities in Nsukka Local Government Area. These interviewees/stakeholders occupy key roles, participate in key binding policy decisions, have the actual power to make changes, and have the important political relational power with other systems (Knoke, 1994) in the Enugu State healthcare delivery system (see Appendix A). The researchers engaged with four key groups of stakeholders in the rural healthcare delivery system (Eze et al., 2016b), specifically, Parents/Guardians, Rural HealthCare Workers (RHCWs), Developers, and Facilitators. According to this classification, the Parents/Guardians (PGs) are individuals that help their children to receive preventative or curative care from the healthcare system; the RHCWs were those directly involved in healthcare processes, they are the direct users of the mHealth tool; the Facilitators were those individuals or bodies that expedite or enable the development, implementation and delivery of mHealth processes, and the Developers were those responsible for building and maintaining the mHealth system.

Empirical data were collected between 2nd and 23rd September 2016, and between 25th February and 25th March 2017 in both Nigeria and Europe. Data collection exercises were conducted at the headquarters of Enugu State's civil service, Ministry of Health (MoH), Enugu State University of Technology and Science Teaching Hospital (ESUT), Local Government Headquarters, health centres in the rural communities in Nsukka Local Government Area Enugu State, and a university in North-West Europe participating in an mHealth project. Ethical approval was obtained in both the primary host institution of the researchers and a local university in Nigeria involved with the research initiative.

Data gathering involved, in-depth interviews, participant observation, and document/record analysis, field notes and photographs from clinics in the target rural communities. All interview participants had been exposed to a new mHealth tool for accessing, classifying and treatment of children under the age of 5. Interview questions therefore focused on this app, though much of the discussion ended up being at the level of mHealth more generally. Interviews were conducted in Igbo or English languages and recorded (with informed consent) for subsequent analysis. All recordings were transcribed verbatim into English, along with the written notes from interviews. Contact time averaged 240 minutes for each group of stakeholders. Initial interview questions are available in the Appendixes B, C, D, and E. Additional paper-based documentation included Standard Operation Procedure (SOP); facility registers, summary form, wall photographs of HIS related charts, graphs, and paper forms. These documents were reviewed in order to get a background information about Enugu State's HIS and to validate data from interviews and observations.

\subsection{Analysis}

Grounded theory (GT) coding techniques (Corbin \& Strauss, 1990, 2008, 2014; Glaser \& Strauss, 1967) were applied to expand on preliminary theorising in this study. GT coding techniques are appropriate in this study for two reasons: First, when theorising is exploratory (Gasson, 2004; Glaser \& Strauss, 1967), as it is here, GT techniques help researchers to generate, or discover theory (Glaser, 2017). Second, GT techniques use a systematic set of procedures to inductively derive theory about a given phenomenon (Corbin \& Strauss, 1990, 2008, 2014; Strauss \& Corbin, 1998). In this way, GT techniques enable researchers to remain close to the studied environments and to develop an integrated set of theoretical concepts from their empirical data-sets (Charmaz, 2011; Urquhart, 2000). These techniques not only help researchers to synthesize and interpret data, but also help to show relationships in the analysis of data (Charmaz, 2011, 2014). Thorough description of coding is presented in Appendix F. 
Potential inconsistency or misinterpretation of data during the coding processes were minimised in four ways. First, the emerging themes were discussed (among researchers) and compared with insights generated that collaborated with secondary literature. Second, findings were made known to stakeholders as a form of 'venting' or 'member checking' exercise, thus testing the validity and reliability of our interpretation (Borman, LeCompte, \& Goetz, 1986; Miles \& Huberman, 1994). Third, collaboration with stakeholders/participants who were actively involved as co-researchers further added to the credibility of our accounts (Creswell \& Miller, 2000). Fourth, data transcripts were revisited and recoded to set the final themes and constructs which reinforces the validity and trustworthiness of the research (Roberts, Priest, \& Traynor, 2006). That is, revisiting transcripts during the coding and constructs framing processes helped to ensure trust and rigor in the method adopted. In the next section, we present the research findings regarding the core categories resulting from the data analysis and the other major categories influencing them.

\section{Findings and theory building}

This research identified the factors that influence the primary appraisal of an mHealth tool in developing countries, the refined model is illustrated in Figure 4 . The figure shows the categories and concepts that emerged from the data. This process of identification of key concepts that describe the results of the primary appraisal is proposed as the initial step towards the adoption and implementation of an mHealth tool in developing countries. We make no claim that the concepts presented here are exhaustive.

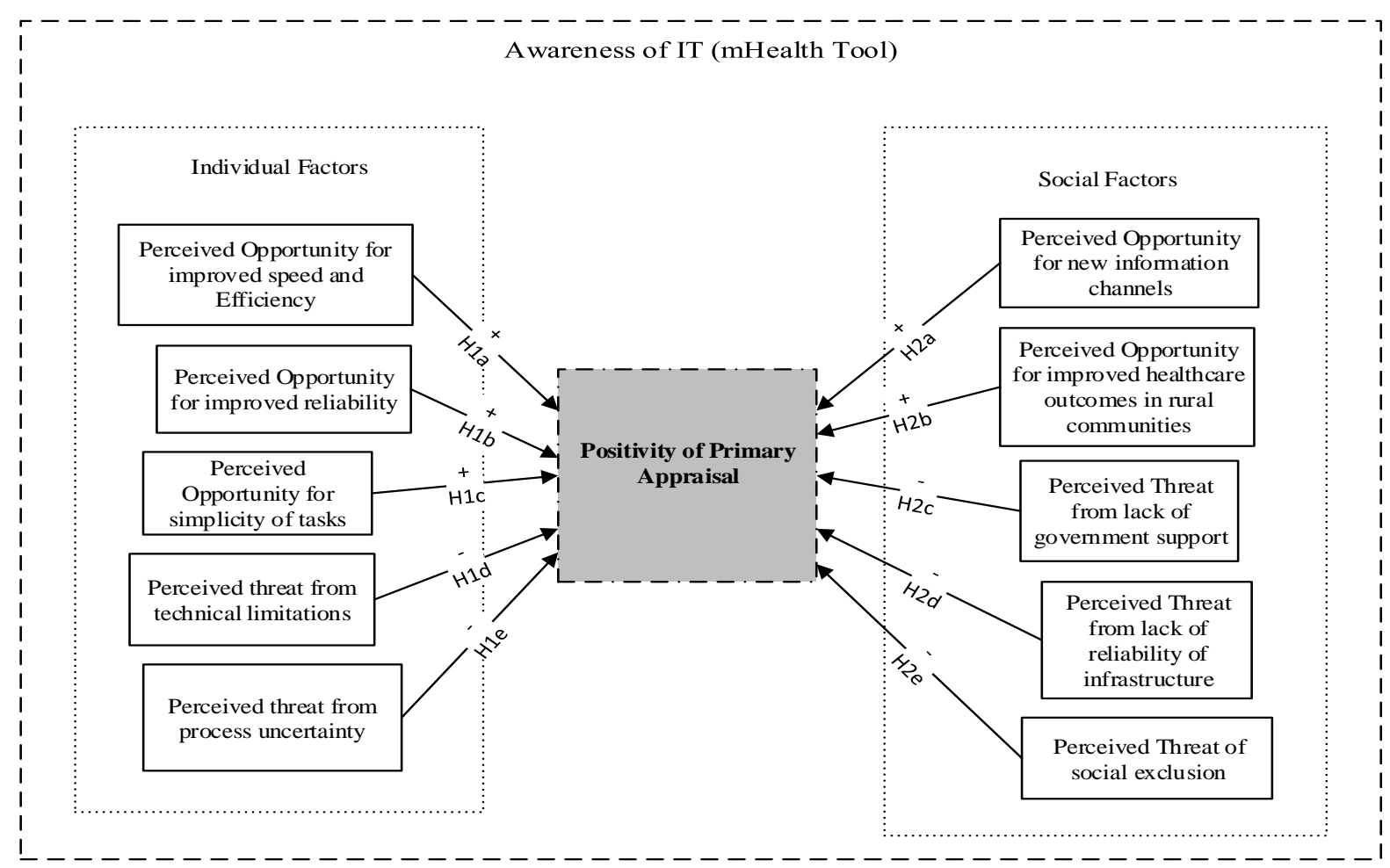

Figure 4-Refined Research Model

Proposition 1 was supported, as five constructs emerged relating to individual threat and opportunity appraisals: Perceived opportunity for improved speed and efficiency, perceived opportunity for improved reliability, Perceived opportunity for simplicity of tasks, Perceived threat from technical limitations, and Perceived threat from process uncertainty. Proposition 2 was also 
supported, as five constructs emerged relating to social threat and opportunity appraisals: Perceived opportunity for new information and communication channels; Perceived opportunity for improved healthcare outcomes in rural communities; Perceived threat from lack of government support; Perceived threat from lack of reliability of infrastructure, and Perceived threat from social exclusion. The following sections describe these emerging constructs in a refined model, as well as the themes that characterised them.

\subsection{Positivity of stakeholders' primary appraisal of an IT in their environment}

Positivity of primary appraisal was characterised by two themes, illustrated in Table 1 . These themes collectively explain the results of the influential role of the individual and social factors on the stakeholders' primary appraisal process - positive or negative. These are evident in the stakeholders' accounts of the expected perceived impacts of mHealth tool on 1) the performance of RHCWs (direct users of the mHealth tool), 2) the reliability of results thereof from clinics, and 3) the lifesaving outcomes for the communities in the long run. The first variable (opportunity) suggests that positive appraisal would be greatest when stakeholders perceive that they have all they need, internally and externally, to support the use of the mHealth tool.

The second theme suggests negative appraisal is high when stakeholders perceive a lack of internal or external resources needed to make use of an mHealth tool in their workplace. These may take a variety of forms, e.g. resources, training and support. However, their absence means stakeholders feel likely to become overwhelmed or isolated and unable to perform tasks with the expected levels of efficiency and reliability.

\begin{tabular}{llrl}
\hline Construct & Explanation & Themes: Stakeholders believes that... \\
\hline $\begin{array}{l}\text { Positivity of } \\
\text { primary }\end{array}$ & $\begin{array}{l}\text { The extent to } \\
\text { appraisal. }\end{array}$ & $\begin{array}{l}\text { Stakeholders are reassured by resources that are being made } \\
\text { stakeholder } \\
\text { believes the new } \\
\text { mHealth tool will } \\
\text { improve conditions }\end{array}$ & $\begin{array}{l}\text { available to make productive use of the new mHealth tool. } \\
\text { Stakeholders are concerned that key resources are missing } \\
\text { and the impact of the new mHealth tool will ultimately not } \\
\text { provide the expected value. }\end{array}$ \\
& & \\
\hline
\end{tabular}

Table 1 - Themes for stakeholders' positivity of primary appraisal

\subsection{Emerged constructs around individual factors}

Five constructs emerged for individual factors. The first is the perceived opportunity for improved speed and efficiency. Three themes emerged around this construct, illustrated in Table 2. The first theme describes the potential for improving the rate at which stakeholders could perform basic tasks, e.g. "I believe it will make our job faster" (RHCW2). The second theme concerns the potential to reduce costs associated with transferring health data to the MoH. Health data could easily be transferred via internet into the central database by the click of a button; a significantly simpler alternative to the current method of transporting hardcopies of health records by road, e.g. "No more paying for transportation to all the places where you are required to send the data, so you just click a button and the data goes wherever" (RHCW5). The third theme describes an expected reduction in time spent by Parents/community members at the healthcare centres during diagnosis and treatment. Several stakeholders saw the use of the mHealth tool as a way of quickly going through the process of diagnosis and treatment in a much shorter period, e.g. "With this mHealth tool we will not be wasting too much time at the centre, since the tool will make them work faster" (Parent7). 
In stakeholders' terms, the perceived opportunity for improved speed and efficiency was seen as an important factor that would influence positive appraisal of the mHealth tool. Thus:

H1a. Stakeholders' perceived opportunity for improved speed and efficiency will result in a positive primary appraisal

\begin{tabular}{ll}
\hline \multicolumn{1}{c}{$\begin{array}{c}\text { Constructs } \\
\text { (Axial Codes) }\end{array}$} & \multicolumn{1}{c}{$\begin{array}{c}\text { Explanation } \\
\text { (Theoretical Memos) }\end{array}$} \\
\hline $\begin{array}{l}\text { Perceived opportunity } \\
\text { for improved speed }\end{array}$ & $\begin{array}{l}\text { Stakeholders believe } \\
\text { new practices will be } \\
\text { and efficiency }\end{array}$ \\
& $\begin{array}{l}\text { less demanding of } \\
\text { their time }\end{array}$
\end{tabular}

Perceived opportunity for improved reliability

Perceived opportunity for simplicity of tasks

Perceived threat from technical limitations

Perceived threat from process uncertainty
Stakeholders believe new practice will be less demanding of rework and error correction

Stakeholders believe new practices will be less demanding in terms of their concentration and understanding Stakeholders believe the technical resources will be insufficient for new practices
Themes: Stakeholders believe that by using the mHealth tool (Open Codes)

- There is a perceived opportunity for improved speed and efficiency for diagnosis and treatment among stakeholders

- There is a perceived opportunity for improved speed and efficiency for capturing and sending (uploading) health data by stakeholders

- There is a perceived opportunity for improved speed and efficiency for diagnosis and treatment time spent at rural healthcare centres among stakeholders

- $\quad$ There is a perceived opportunity for improved reliability of diagnosis and treatment results among stakeholders

- $\quad$ There is a perceived opportunity for improved reliability of results among stakeholders from rural healthcare centres

- There is a perceived opportunity for improved reliability health data entries among stakeholders

- There is a perceived opportunity for simplicity of diagnosis and treatment procedures among stakeholders

- $\quad$ There is a perceived opportunity for simplicity of health data handling among stakeholders

- There is a perceived threat from the technical limitation of mHealth is respect to task execution among stakeholders

- There is a perceived threat from technical limitation of the features regarding other diagnosis and treatments among stakeholders

- There is a perceived threat from technical limitation regarding the sturdiness of the mHealth tool among stakeholders

- There is a perceived threat from process uncertainty for the in-built tasks among stakeholders

- There is a perceived threat from process uncertainty in procedural healthcare steps among stakeholders

- There is a perceived threat from process uncertainty when interacting with the community's values and norms among stakeholders

Table 2 - Themes for each of the emerging constructs relating to individual factors. 
The second construct was the perceived opportunity for improved reliability, which manifested three distinct themes. The first theme described stakeholders' anticipation that the quality of diagnosis and treatment outcomes from rural health centres would improve e.g. "mHealth tool will help RHCWs in making better decisions resulting in improved quality of diagnosis and treatment" (Parent5). The second theme was stakeholders' perception that results from the new system would be more reliable, e.g. "It might bring changes, because right now from the way I am seeing things, people will tend to trust [have faith on] devices and people will trust being diagnosed with devices" (Parent2). The third theme describes RHCWs' anticipation that new systems could implement error-proof data entry forms for rural healthcare centres, e.g. "I know that using mHealth tool will help in reducing errors in our treatment" (RHCW6). Stakeholders were acutely aware that records are not always accurate; an issue that creates frequent and unwelcome uncertainty during the diagnosis and treatment process.

Improved reliability was seen by stakeholders as a significant factor that would influence positive appraisal for mHealth tools. Thus:

H1b. Stakeholders' perceived opportunity for improved reliability will result in a positive primary appraisal

The third construct was the perceived opportunity for simplicity of tasks. Two themes emerged within this construct. The first theme describes that most stakeholders believe an mHealth tool would make RHCWs tasks effortless compared with the existing paper format, e.g. "The app is easy to locate on the phone; you can easily use it. It is good, the guide is there for you" (RHCW7). For some, it referred to the easy understanding of their tasks when using the mHealth tool, e.g. "it is easy for me to manipulate this tool, the app as I can say is very comfortable at our own level" (RHCW3). The second theme describes the simplification of data management for stakeholders, e.g. "Data recording is not needed. As you progress through the app, data is being saved and stored for you at the same time" (RHCW2). This appealed to stakeholders, for whom data recording was often a cumbersome secondary activity distracting them from core treatment and diagnosis responsibilities.

Perceived opportunity for simplicity of tasks was also identified. Stakeholders' were enthusiastic about the possibility of an mHealth tool simplifying and improving their tasks. This was identified as a significant factor that would influence a positive primary appraisal. Thus:

H1c. Stakeholders' perceived opportunity for simplicity of tasks will result in a positive primary appraisal

The fourth construct was the perceived threat from technical limitations, which manifested three themes. The first theme was the concern around the technical limitation features of the mHealth tool in performing the envisaged tasks. Stakeholders raised concerns regarding how well the mHealth tool performs the diagnosis and treatment tasks e.g. "if they have overwhelming failure in the app then that can put a lot of people off" (Developer6). This implies that a first-time user could be influenced to reject an application that is not performing as one anticipated. The second theme expressed concerns around the limited technical features of the mHealth tool regarding treatments e.g. "I feel that the app development should go further than the stage it is at now, for example, the issue of treatment is still being done manually" (Facilitator1). For others, it goes much deeper, they want the mHealth tool to be used in treating adults, e.g. "I want the tool to be developed to include adults, like pregnant 
women" (RHCW4). That is, if mHealth tool could not be used to do these other activities that he/she would have wished it could do, then, he or she might negatively appraise it. The third theme expressed concerns around the technical limitations regarding the ruggedness features of the mHealth tool e.g. "the smartphone looks fragile and might break when it falls, so, one would like to use a tool that could break incurring damages from user" (Facilitator2).

Technical limitations were highlighted by stakeholders as one of the significant factors that would influence a negative appraisal for the mHealth tool. Thus:

H1d. Stakeholders' perceived threat from technical limitations will result in a negative primary appraisal

The fifth construct was the perceived threat from process uncertainty, which exhibited three themes. The first theme explained the anxiety felt by stakeholders with regard to using computers, e.g. "I have not used a computer before, I do not know whether I can use it" (RHCW5). To some stakeholders the prospect of using technology evoked a deep emotion, e.g. "for some of us it will be hard you know, I feel too old now to start learning how to use computer, well we will see" (Facilitator6). The second theme describes the concern by stakeholders that mHealth introduction might alter current work practices, e.g. "People find it very difficult to change from their comfort zones, they feel uncomfortable to change to an unknown way of doing things" (Facilitator3). The third theme describes the effect of norms and cultural values that may negatively influence stakeholders' behaviour towards the mHealth tool, e.g. "people in rural communities liken technology as a sign that we are nearing the end of the world [end-time] due to their beliefs" (Facilitator1).

Process uncertainty was also identified by stakeholders as a convincing factor that would influence a negative appraisal for the mHealth tool. Thus:

H1e. Stakeholder's perceived threat from process uncertainty will result in a negative primary appraisal.

\subsection{Emerged constructs around the social factors}

Five constructs emerged around the social factors, themes for which are illustrated in Table 3. The first construct was the perceived opportunity for new information and communication channels, which exhibited two themes. The first theme describes the new communication channels between stakeholders, e.g. "It will create communication between rural healthcare officers and patients regarding health-related matters" (RHCW6). For others, new information channels created more potential for supervision, e.g. "It will help open up conversation between rural healthcare officers and their superiors about their tasks" (Developer5). The second theme describes a new source of health information through the internet, e.g. "With the phone, people would be looking for diagnosis or treatment about ailments in the net" (Facilitator1).

Stakeholders identified perceived opportunity for new information and communication channels as a compelling factor that would influence positive primary appraisal of an mHealth tool. Thus:

H2a. Stakeholders' perceived opportunity for new information and communication channels will result in a positive primary appraisal

The second construct was the perceived opportunity for improved healthcare outcomes in rural communities, which displayed two themes. The first theme highlighted the impact such a healthcare delivery tool would have on rural community members, e.g. "It could create a happier community since this could mean that less children would be dying from childhood diseases" (Facilitator4). The general impression among stakeholders is that using mHealth tool 
in rural communities would encourage members to send their children for diagnosis and treatment, e.g., "Once they [Parents] know that we are using phone [mHealth tool], they would rush [avail of such opportunity] for it" (RHCW3). There is also the belief that the work ethic of stakeholders would improve tremendously as a result of mHealth introduction in Enugu State healthcare system. For example, stakeholders would be motivated to work in rural healthcare centres, e.g. "it would improve my confidence and I would be respected in my community for using mHealth tool" (RHCW1). The second theme concerns the 'reach' capacity of an mHealth tool, e.g. "Using mHealth tool by RHCWs is the best way to bring treatment to the rural communities" (Developer5). That is, the mHealth tool would help in extending healthcare services to rural community members into the healthcare systems.

Perceived opportunity for improved diagnosis and treatment was seen by stakeholders as a substantial factor that would influence primary positive appraisal of an mHealth tool. That is, positive response to the external impact on the healthcare services that is quite different from internal (self) impact. Thus:

H2b. Stakeholders' perceived opportunity for improved diagnosis and treatments will result in a positive primary appraisal

The third and the most frequently discussed construct described the perceived threat from lack of government support. This construct is considered to be the most persuasive, as it emphasises the need for government approval and support for the mHealth implementation process. The nature of the support expected from government is varied. Government support significantly plays a central role in moderating the effect of negative appraisals. The first theme focused on the origin of the mHealth tool e.g. "You have to convince these policy makers seriously [persuasively] before they can buy-into it, we need to convince them that this [mHealth tool] belongs to them" (Facilitator1). This suggests that for successful implementation of mHealth tool in Enugu State, policy-makers would need to be co-opted as partners in its introduction, for example, policy-makers would need to enact laws and regulations to afford the provision of healthcare via mHealth a legal status in the healthcare delivery system. The second theme refers to the concern around the consistency in policy implementation by successive governments, e.g. "One of the things I have seen is, you know somersaults, inconsistency in implementing policies and things they set out to do" (Developer5). Implying there is a lack of consistency on the part of governments regarding policy implementation. Often, a change of government means policies are reversed or tweaked in such a way as to suit the new government agenda. The third theme centred on the concern by stakeholders for the provision of adequate financial resources. Stakeholders expect the government to provide financial support and the needed incentives to stimulate the use of an mHealth tool, e.g. "mHealth implementation could be jeopardised by lack of funds, and its sustainability depends on the availability of funds as well" (Facilitator4). The fourth theme describes the concern around the provision of training for users. For some, lack of training could mean not doing their tasks as expected e.g. "it is a new app that are going to have to be embedded within their daily work practices, and for this to work, they have to be trained properly on how to use it" (Developer2). For others, it has much deeper implications, e.g., "without good training, it may have a consequential effect on the continued use of mHealth for a long time after its introduction, the tool could be abandoned" (Facilitator5). The fifth theme is the concern expressed by stakeholders around the need for supervision during mHealth tool use. This theme stressed the importance of supervising users during use to make sure that the mHealth tool is used as 
anticipated, e.g. "they will also need a lot of supervision from their superiors to make sure they are doing the correct thing" (Facilitaor6).

\begin{tabular}{|c|c|c|}
\hline Constructs & Explanation & Themes: Stakeholders believe that by using the mHealth tool \\
\hline $\begin{array}{l}\text { Perceived } \\
\text { opportunity for } \\
\text { new information } \\
\text { and } \\
\text { communication } \\
\text { channels }\end{array}$ & $\begin{array}{l}\text { Stakeholders believe } \\
\text { new practices will be } \\
\text { less demanding of } \\
\text { existing social } \\
\text { connections }\end{array}$ & $\begin{array}{l}\text { - There is a perceived opportunity for new information } \\
\text { and communication channels among stakeholders - } \\
\text { between RHCWs and Parents, with RHCWs, and } \\
\text { RHCWs and their supervisors or superiors } \\
\text { - There is a perceived opportunity for new information } \\
\text { and communication channels through internet for } \\
\text { Parents and community members at large }\end{array}$ \\
\hline $\begin{array}{l}\text { Perceived } \\
\text { opportunity for } \\
\text { improved } \\
\text { healthcare } \\
\text { outcomes in rural } \\
\text { communities }\end{array}$ & $\begin{array}{l}\text { Stakeholders believe } \\
\text { new practices will be } \\
\text { less demanding of } \\
\text { subsequent ancillary } \\
\text { or emergency care }\end{array}$ & $\begin{array}{l}\text { There is a perceived opportunity for improved } \\
\text { healthcare outcomes as mHealth tool introduction } \\
\text { would lead to less under-five deaths } \\
\text { There is a perceived opportunity for improved } \\
\text { healthcare outcomes in rural communities since } \\
\text { healthcare services would reach the unserved }\end{array}$ \\
\hline $\begin{array}{l}\text { Perceived threat } \\
\text { from lack of } \\
\text { government } \\
\text { support }\end{array}$ & $\begin{array}{l}\text { Stakeholders believe } \\
\text { the government } \\
\text { support will be } \\
\text { insufficient for new } \\
\text { practices }\end{array}$ & $\begin{array}{l}\text { - There is a perceived threat from lack of government } \\
\text { support with regards to participation or partnering } \\
\text { There is a perceived threat from lack of government } \\
\text { support by the creation of enabling policies for mHealth } \\
\text { tool implementation and upscaling } \\
\text { - There is a perceived threat from lack of government } \\
\text { support for the provision of required or necessary } \\
\text { funding for implementation and sustainability } \\
\text { - There is a perceived threat from lack of government } \\
\text { support to provide training for end-users } \\
\text { There is a perceived threat from the lack of government } \\
\text { support in the areas of supervision and monitoring }\end{array}$ \\
\hline $\begin{array}{l}\text { Perceived threat } \\
\text { from lack of } \\
\text { reliability of } \\
\text { infrastructure }\end{array}$ & $\begin{array}{l}\text { Stakeholders believe } \\
\text { the infrastructure will } \\
\text { be insufficient for } \\
\text { new practices }\end{array}$ & $\begin{array}{l}\text { - There is a perceived threat from lack of reliability of } \\
\text { infrastructure with regards to internet availability } \\
\text { - There is a perceived threat from lack of reliability of } \\
\text { infrastructure with regards to steady supply of power } \\
\text { (electricity) }\end{array}$ \\
\hline $\begin{array}{l}\text { Perceived threat } \\
\text { from social } \\
\text { exclusion }\end{array}$ & $\begin{array}{l}\text { Stakeholders believe } \\
\text { the consideration of } \\
\text { personal roles will be } \\
\text { insufficient for new } \\
\text { practices }\end{array}$ & $\begin{array}{l}\text { - There is a perceived threat from social exclusion for } \\
\text { doctors who might feel that their primary job is being } \\
\text { taken away by the introduction of mHealth tool } \\
\text { - There is a perceived threat from social exclusion for } \\
\text { RHCWs who feel that it might mean the loss of their job }\end{array}$ \\
\hline
\end{tabular}

Table 3 - Themes for each of the emerging constructs relating to social factors.

Perceived threat from lack of government support was viewed by stakeholders as the most significant factor that would influence the primary negative appraisal for mHealth tool. Thus:

H2c. Stakeholders' perceived threat from lack of government support will result in a negative primary appraisal

The fourth construct was the perceived threat from lack of reliability of infrastructure. Stakeholders raised concerns around the impact of unreliable infrastructure. The first theme was the concern 
around the non-availability of internet which could hamper the use of the mHealth tool, e.g. "The external networks that could impact on the health care delivery as regards mHealth is internet availability" (RHCW2). Suggesting that in remote areas, the external input, such as poor internet connection could make mHealth use unworkable, being a characteristic feature, it could make people not be enthusiastic about mHealth introduction. The second theme centred on the need for a constant power supply e.g. "The epileptic nature of electricity supply...where people can't even charge their phones or PCs because they don't have light [power] is going to be a big problem for mHealth tool" (Parent2). Stakeholders are referring to the unreliable electricity supplies across Nigeria, which to them could jeopardise the opportunities afforded by mHealth.

Reliability of infrastructure was highlighted as one of the important factors that would influence the primary negative appraisal for mHealth tool. Thus:

H2d. Stakeholders' perceived threat from lack of reliability of infrastructure will result in a negative primary appraisal

The fifth construct was the perceived threat from social exclusion. Stakeholders are concerned that mHealth introduction into Enugu State healthcare system could bring along with it such issues as social exclusion and class distinction. The first theme made reference to the anxiety that an mHealth tool will reduce their job security, e.g. "I am worried that it might make some of us redundant in our work place" (RHCW3). This perception stems from the deduction that using an mHealth tool could mean executing more tasks than one or more RHCWs at any given time, thus rendering some of them redundant. These redundant workers could be sacked or reassigned. The second theme focused on the job status of some stakeholders (e.g., doctors). For some, implementing mHealth technologies might mean losing the professional autonomy they have over diagnosis and treatment, e.g. "Some doctors may not accept it for given away their primary duty" (Developer6). These concerned stakeholders argue that diagnosis and treatments are at the core of their profession, so, why give it away to other stakeholders by way of mHealth technologies.

Perceived threat from social exclusion was identified as one of the factors that would influence a negative primary appraisal. Thus:

\section{H2e. Stakeholders' perceived threat from social exclusion will result in a negative primary appraisal}

\section{Discussion}

This paper explores the factors that influence stakeholders' primary appraisal of mHealth technologies in rural contexts. The analysis in the previous section presents several important findings.

First, opportunity was found to play an important role in explaining the internal and external factors that positively (positivity) influence stakeholders' primary appraisal via five constructs. The perceived opportunity for improved speed and efficiency construct describes the stakeholders' opinions that captured the practical benefits that mHealth would have on healthcare delivery (e.g. Gurman, Rubin, \& Roess, 2012; Paina \& Peters, 2011). Such internal perception for an opportunity for improved speed and efficiency may lead to stakeholders' positive appraisal of an IT tool and may ultimately influence intention to use (Beaudry, 2009; Claggett, 2010). Stakeholders' beliefs that using mHealth tool would result in improved quality data, diagnosis and treatment emanated from the perceived opportunity for improved 
reliability construct. These perceptions are consistent with existing literature (e.g. Akter, D'Ambra, \& Ray, 2010; Chib et al., 2015). Self-efficacy which emanates from the stakeholders' beliefs about their abilities emerged within the perceived opportunity for simplicity of tasks construct. Self-efficacy perception reflects an individual's internal beliefs in his/her own capabilities to perform a sequence of action to meet a given social demand (healthcare delivery) (Ajzen, 2002; Barbeite \& Weiss, 2004). Self-efficacy has been found in literature to influence positive appraisal of an IT tool and intention to engage (e.g. Agarwal, Sambamurthy, \& Stair, 2000; Ajzen, 2002). This specifically holds true for mHealth tool in research conducted by Xue et al. (2015) in Ethiopia. They posit that perceived behavioural control which could be aligned with self-efficacy can make individuals more motivated to perform a target behaviour (goal) (Xue et al., (2015). The perceived opportunity for new information and communication channels construct arose out of the stakeholders' perceptions around these other 'things' that one could use the mHealth tool for. This positive influencing factor emerged from interacting with the material agency of mHealth tool (external material). One such activity is third party information access via the internet. Parents could access health information available in the Internet, but this space is unregulated and may jeopardise the structured healthcare delivery processes meant for rural communities (Moreland, French, \& Cumming, 2016; Murray et al., 2003). The other is the new communication channels between stakeholders created by the availability of these mobile tools. Patients could reach RHCWs through this tool, it facilitates communication amongst RHCWs and between RHCWs and their supervisors (e.g. Higgs et al., 2014; Leon, Schneider, \& Daviaud, 2012). The perceived opportunity for improved healthcare outcomes in rural communities construct emerged from the stakeholders' belief that healthcare services would reach the unserved in rural areas. That is, the positive external impacts of using an mHealth tool. These findings resonate with previous work demonstrating how perceived improvement in health outcomes could influence stakeholders' decision-making process towards positively appraising an mHealth tool (Aranda-Jan, Mohutsiwa-Dibe, \& Loukanova, 2014; Miah, Hasan, Hasan, \& Gammack, 2017).

Second, threat was found to play a significant role in delineating the internal and external factors that negatively influence stakeholders' primary appraisal of an mHealth tool through five constructs. The perceived threat from technical limitation construct emerged for the stakeholders' internal concerns around technical functionalities and limited capabilities (J.-N. Lee, Huynh, \& Hirschheim, 2008; Lim, Benbasat, \& Ward, 2000) of the mHealth tool (Chang et al., 2013). First impression has been shown to influence the decision-making process to either positively (opportunity) or negatively (threat) appraise an IT tool (Kim, Shin, \& Lee, 2009; Nicolaou \& McKnight, 2006). First impression is considered a significant factor in an appraisal process, since one may not get a second chance to test-out a particular IS tool (Frost, Pike, \& Kenyo, 2008; Reinecke et al., 2013). Limited capabilities were found to influence stakeholders' decisions to either positively or negatively appraise an mHealth tool. This finding resonates with evidence in literature regarding stakeholders' high expectation of an mHealth tool (Chang et al., 2013).

The perceived threat from process uncertainty construct emerged for stakeholders' internal perception of concerns around the fear of computers, pre-existing practices, and counter interactions with culture and norms. Computer anxiety arises out of the fear of computers when using a computer or fearing the possibility of using one in the future (Barbeite \& Weiss, 2004; Shu, Tu, \& Wang, 2011). Findings in literature echo previous works demonstrating the influence of computer anxiety on primary appraisal that impacts intention (e.g. Fagan, Neill, 
\& Wooldridge, 2004; Venkatesh, 2000). Habit as one of the perceived threats has been identified in previous works (Maier, Laumer, Weinert, \& Weitzel, 2015; Recker, 2014). Habit could be defined as an acquired or cultured behavioural sequences of acts to achieve a specific goal (De Guinea \& Markus, 2009; Polites, 2005). In IS research pre-existing practice or habit is a critical predictor of technology use (Polites, 2005; Venkatesh, Thong, \& Xu, 2012). Cultural and social norms was found to influence stakeholders' decisions (e.g. Carter \& Weerakkody, 2008; Srite \& Karahanna, 2006). In the context of this study, culture could be defined as communicable knowledge produced across humanity's social life (Im, Hong, \& Kang, 2011; Jahoda, 2012). The perceived effect of culture and social norms have important conceptual similarity with habit. In that vein, one could infer that since technology is generally used in cultural contexts, culture can be said to play a significant role in technology appraisal (Im et al., 2011).

The perceived threat from lack of government support construct emerged for stakeholders' concerns around government support for mHealth intervention. This concern resonates with previous work showing the influence of government support on primary appraisal of an IT. For example, lack of support from governments (external to the user) in areas of promulgation of enabling policy, high level strategic planning and financial support have shown to inhibit implementation of mHealth in developing countries (e.g. Leon et al., 2012; Mechael, 2009). Funding shortages have been found to discourage users to continue with mHealth services (Chib, 2010; Chib, Lwin, Ang, Lin, \& Santoso, 2008). Absence of this support may lead to negative (threat) primary appraisal of an mHealth tool (Aranda-Jan et al., 2014; Leon et al., 2012). Support in areas of training and supervision has been shown to lead to positive or negative appraisals. Evidence of the need for these types of support is found in existing literature (e.g. Leon et al., 2012; Modi et al., 2015).

The perceived threat from lack of reliability of infrastructure construct reflects the reality that the non-availability of power supply and internet access could pose negative influence on the successful implementation of mHealth in developing countries (Akter et al., 2010; Sanner, Manda, \& Nielsen, 2014). Threat appraisal of the reliability of infrastructure which is an external factor is particularly significant for stakeholders in rural communities where power outages and network coverages are more pronounced.

The perceived threat from social exclusion construct manifested for stakeholders' concerns around the internal fear for technology and job loss as a result of introducing an mHealth tool (Chang et al., 2013; Maeder, 2014). Some stakeholders expressed concern for the security of their jobs as the introduction of an mHealth tool might mean fewer workers would be required (Chang et al., 2013; Xue et al., 2015). Other stakeholders (e.g., Doctors) expressed concern over the possible change to the traditional way treatments are done (Desai, Khan, Mistry, \& Gaikawad, 2016; Malvey \& Slovensky, 2014). For others, it could mean the loss of autonomy where a skilled professional is acting exclusively on the guidance of a specialist located at a remote area (Morrison, Shrestha, Hayes, \& Zimmerman, 2013).

\section{Summary and Conclusion}

The study developed a novel research model that describes how primary appraisal influences the introduction of an mHealth tool in a new context. In the model, the emergent constructs from both the individual and social factors combine to tell a story of how primary appraisal could positively or negatively affect mHealth introduction in rural communities of developing 
countries. The model presents a set of individual and social factors that governments, funding bodies and non-governmental organisations should consider before embarking on the introduction of an mHealth tool in rural communities of developing countries. At the individual level, the perceived opportunities for improved speed and efficiency, reliability of results, and simplification of tasks by the tool were seen on as possible motivating factors that would influence stakeholders to positively appraise a new mHealth tool. The perceived threats from the technical limitations of the tool's functionalities, and process uncertainty were seen by stakeholders to negatively impact the introduction of an mHealth tool. At the social level, the perceived opportunities for new information and communication channels and improved availability of healthcare services would positively impact on the primary appraisal. Yet, the perceived threats from lack of government support, lack of reliable infrastructure, and the resultant social exclusion associated with the introduction of an mHealth tool were seen by stakeholders to negatively affect primary appraisal.

This research has several important contributions to research and practice. First, the model offers new perspectives for researchers into the primary appraisal processes and dynamics involved in the introduction of mHealth tools for new areas of developing countries. Second, the model offers a new way to understand how users arrive at their primary appraisal behaviour and thus can provide a useful framework through which we can incorporate adoption and resistance studies (Eze, Gleasure, \& Heavin, 2016a). This contribution could be considered significant in modelling the factors that influence primary appraisal. Third, it is envisaged that by understanding the process of primary appraisal, either as an opportunity or a threat, practitioners and organisations will support positive appraisal and minimise the occurrence of negative ones when introducing mHealth tools. Fourth, this research contributes to the growing evidence that the cognitive processes can be broken down into internal and external components (e.g. Aizawa, 2017; Braver, 2012; Paradis, 2011; Wedgwood, 2006). The findings of this study were not without some limitations. First, the study made use of a singlecase design, and thus make no claims of statistical generalisability (Yin, 2013). Second, the study was exploratory in nature. We therefore recommend a longitudinal study that could reveal other contributing factors that may arise due to re-appraisal processes, as users may reevaluate and adjust their prior primary and/or secondary appraisals (Beaudry \& Pinsonneault, 2005; Bhattacherjee et al., 2017). Third, the research focused on technology-enabled guidelinedriven treatment of the mHealth delivery service. Other forms of mHealth initiatives exist, e.g. those focused on data gathering (Chang et al., 2011; Medhanyie et al., 2015) or those focused on remote diagnosis and treatment (Hufnagel, 2012; Knoble \& Bhusal, 2015). We, therefore, call for similar research on other delivery approaches in order to compare findings.

\section{References}

Abraham, C., Boudreau, M.-C., Junglas, I., \& Watson, R. (2013). Enriching our theoretical repertoire: the role of evolutionary psychology in technology acceptance. European Journal of Information Systems, 22(1), 56-75.

Agarwal, R., Sambamurthy, V., \& Stair, R. M. (2000). The evolving relationship between general and specific computer self-efficacy-An empirical assessment. Information Systems Research, 11(4), 418-430.

Aizawa, K. (2017). Cognition and behavior. Synthese, 194(11), 4269-4288. 
Ajzen, I. (2002). Perceived behavioral control, self-efficacy, locus of control, and the theory of planned behavior. Journal of Applied Social Psychology. 32(4), 665-683.

Aker, J. C., \& Mbiti, I. M. (2010). Mobile phones and economic development in Africa. Center for Global Development Working Paper(211).

Akter, S., D'Ambra, J., \& Ray, P. (2010). User perceived service quality of m-Health services in developing countries. Paper presented at the 18th European Conference on Information Systems (pp. 1-12), Pretoria, South Africa: University of Pretoria.

Alam, M., Khanam, T., \& Khan, R. (2010). Assessing the scope for use of mobile based solution to improve maternal and child health in Bangladesh: A case study. Paper presented at the International Conference on Information and Communication Technologies and Development, London, UK.

Aldwin, C. M. (2007). Stress, coping, and development: An integrative approach. New York, NY: Guildford.

Andriopoulos, C., \& Lowe, A. (2000). Enhancing organisational creativity: the process of perpetual challenging. Management Decision, 38(10), 734-742.

Aranda-Jan, C. B., Mohutsiwa-Dibe, N., \& Loukanova, S. (2014). Systematic review on what works, what does not work and why of implementation of mobile health (mHealth) projects in Africa. BMC Public Pealth, 14(1), 188.

Avey, J. B., Luthans, F., \& Youssef, C. M. (2010). The additive value of positive psychological capital in predicting work attitudes and behaviors. Journal of Management, 36(2), 430-452.

Barbeite, F. G., \& Weiss, E. M. (2004). Computer self-efficacy and anxiety scales for an Internet sample: testing measurement equivalence of existing measures and development of new scales. Computers in Human Behavior, 20(1), 1-15.

Beaudry, A. (2009). Coping with information technology Handbook of Research on Contemporary Theoretical Models in Information Systems (pp. 516-528): IGI Global.

Beaudry, A., \& Pinsonneault, A. (2005). Understanding user responses to information technology: A coping model of user adaptation. MIS Quarterly. 493-524.

Bhattacherjee, A., Davis, C. J., Connolly, A. J., \& Hikmet, N. (2017). User response to mandatory IT use: a Coping Theory perspective. European Journal of Information Systems, $1-21$.

Bohm, A. (2004). 5.13 Theoretical Coding: Text Analysis in Grounded Theory. A Companion to Qualitative Research. 270.

Böhm, A. (2004). Theoretical coding: text analysis in grounded theory. Dans U. Flick, E. von Kardorff, \& I. Steinke (Éds), A companion to qualitative research (pp. 270-275): London: Sage.

Borman, K. M., LeCompte, M. D., \& Goetz, J. P. (1986). Ethnographic and qualitative research design and why it doesn't work. American Behavioral Scientist. 30(1), 42-57.

Braver, T. S. (2012). The variable nature of cognitive control: a dual mechanisms framework. Trends In Cognitive Sciences. 16(2), 106-113. 
Carter, L., \& Weerakkody, V. (2008). E-government adoption: A cultural comparison. Information Systems Frontiers, 10(4), 473-482.

Chang, L. W., Kagaayi, J., Arem, H., Nakigozi, G., Ssempijja, V., Serwadda, D., . . Reynolds, S. J. (2011). Impact of a mHealth intervention for peer health workers on AIDS care in rural Uganda: a mixed methods evaluation of a cluster-randomized trial. AIDS and Behavior, 15(8), 1776-1784.

Chang, L. W., Njie-Carr, V., Kalenge, S., Kelly, J. F., Bollinger, R. C., \& Alamo-Talisuna, S. (2013). Perceptions and acceptability of mHealth interventions for improving patient care at a community-based HIV/AIDS clinic in Uganda: a mixed methods study. AIDS Care. 25(7), 874-880.

Charmaz, K. (2006). Constructing grounded theory: A practical guide through qualitative research. SagePublications Ltd, London.

Charmaz, K. (2011). Grounded theory methods in social justice research. The Sage Handbook of Qualitative Research.4(1), 359-380.

Charmaz, K. (2014). Constructing Grounded Theory: 416 pages I SAGE Publications Ltd

Chib, A. (2010). The Aceh Besar midwives with mobile phones project: Design and evaluation perspectives using the information and communication technologies for healthcare development model. Journal of Computer-Mediated Communication, 15(3), 500-525.

Chib, A. (2013). The promise and peril of mHealth in developing countries. Mobile Media $\mathcal{E}$ Communication, 1(1), 69-75.

Chib, A., \& Chen, V. H.-H. (2011). Midwives with mobiles: A dialectical perspective on gender arising from technology introduction in rural Indonesia. New Media \& Society, 13(3), 486501.

Chib, A., Lwin, M. O., Ang, J., Lin, H., \& Santoso, F. (2008). Midwives and mobiles: using ICTs to improve healthcare in Aceh Besar, Indonesia. Asian Journal of Communication, 18(4), 348-364.

Chib, A., van Velthoven, M. H., \& Car, J. (2015). mHealth adoption in low-resource environments: a review of the use of mobile healthcare in developing countries. Journal of Health Communication. 20(1), 4-34.

Chun, C.-A., Moos, R. H., \& Cronkite, R. C. (2006). Culture: A fundamental context for the stress and coping paradigm. Handbook of Multicultural Perspectives on Stress and Coping. Handbook of multicultural perspectives on stress and coping, 29-53.

Claggett, J. L. (2010). Understanding primary appraisal in user adoption: an exploratory case study of a telehealth project. Paper presented at the Proceedings of the Southern Association for Information Systems Conference.

Connolly, A. J., \& Bhattacherjee, A. (2011). Coping with the Dynamic Process of Technostress, Appraisal and Adaptation. Paper presented at American Conference on Information Systems.

Corbin, J., \& Strauss, A. (1990). Grounded theory research: Procedures, canons and evaluative criteria. Zeitschrift für Soziologie, 19(6), 418-427. 
Corbin, J., \& Strauss, A. (2008). Basics of qualitative research: Techniques and procedures for developing grounded theory. (3rd ed.). Thousand Oaks, CA: Sage.

Corbin, J., \& Strauss, A. (2014). Basics of qualitative research: Techniques and procedures for developing grounded theory: Sage publications.

Creswell, J. W., \& Miller, D. L. (2000). Determining validity in qualitative inquiry. Theory Into Practice. 39(3), 124-130.

Datta, P., Byrd, T. A., Okoli, C., \& Mbarika, V. W. (2005). The neglected continent of IS research: A research agenda for sub-Saharan Africa. Journal of the Association for Information Systems, 6(5), 6 .

De Guinea, A. O., \& Markus, M. L. (2009). Why break the habit of a lifetime? Rethinking the roles of intention, habit, and emotion in continuing information technology use. MIS Quarterly. 433-444.

DeRenzi, B., Findlater, L., Payne, J., Birnbaum, B., Mangilima, J., Parikh, T., ... Lesh, N. (2012). Improving community health worker performance through automated SMS. Paper presented at the Proceedings of the Fifth International Conference on Information and Communication Technologies and Development.

Desai, P., Khan, M. S., Mistry, C., \& Gaikawad, V. (2016). Study of Concerns Related to Implementation of M-Health in India: Understanding Urban Doctor's Perspective. International Journal of Computer Applications (0975 - 8887) International Conference on Advances in Information Technology and Management ICAIM - 2016.

Donner, J., \& Mechael, P. (2012). mHealth in Practice: Mobile technology for health promotion in the developing world: A\&C Black.

Elie-Dit-Cosaque, C., \& Pallud, J. (2010). User Adaptation and IS Success: An Empirical Investigation among French Workers. Paper presented at the International Conference on Information Systems.

Elie-Dit-Cosaque, C., Pallud, J., \& Kalika, M. (2011). The influence of individual, contextual, and social factors on perceived behavioral control of information technology: A field theory approach. Journal of Management Information Systems. 28(3), 201-234.

Elie-Dit-Cosaque, C., \& Straub, D. W. (2011). Opening the black box of system usage: user adaptation to disruptive IT. European Journal of Information Systems, 20(5), 589-607.

Eze, E., Gleasure, R., \& Heavin, C. (2016a). How can mHealth applications that are developed in one area of the developing world be adapted for use in others? Journal of Decision Systems. 25(sup1), 536-541.

Eze, E., Gleasure, R., \& Heavin, C. (2016b). Reviewing mHealth in developing countries: A stakeholder perspective. Procedia Computer Science, 100, 1024-1032.

Eze, E., Gleasure, R., \& Heavin, C. (2018). Mobile health solutions in developing countries: a stakeholder perspective. Health Systems, 1-23.

Fadel, K. J., \& Brown, S. A. (2010). Information systems appraisal and coping: the role of user perceptions. Communications of the Association for Information Systems. Communications of the association for information systems, 26(1), 6. 
Fagan, M. H., Neill, S., \& Wooldridge, B. R. (2004). An empirical investigation into the relationship between computer self-efficacy, anxiety, experience, support and usage. Journal of Computer Information Systems, 44(2), 95-104.

Folkman, S., Lazarus, R. S., Gruen, R. J., \& DeLongis, A. (1986). Appraisal, coping, health status, and psychological symptoms. Journal of Personality and Social Psychology. 50(3), 571.

Free, C., Phillips, G., Watson, L., Galli, L., Felix, L., Edwards, P., . . Haines, A. (2013). The effectiveness of mobile-health technologies to improve health care service delivery processes: a systematic review and meta-analysis. PLoS Medicine. 10(1), e1001363.

Frost, R., Pike, J., \& Kenyo, L. (2008). Generating Student Interest in the Information Systems Major: A Strategic Framework for the Introductory Course. Issues in Information Systems, 9(1), 188-195.

Furuholt, B., \& Matotay, E. (2011). The developmental contribution from mobile phones across the agricultural value chain in rural Africa. The Electronic Journal of Information Systems in Developing Countries, 48.

Gasson, S. (2004). Rigor in grounded theory research: An interpretive perspective on generating theory from qualitative field studies. The Handbook of Information Systems Research. 4, 79-102.

Glaser, B. (1978). Theoretical sensitivity: Advances in the methodology of grounded theory: Sociology Pr.

Glaser, B. (2017). Discovery of grounded theory: Strategies for qualitative research: Routledge.

Glaser, B., \& Strauss, A. (1967). Grounded theory: The discovery of grounded theory. Sociology The Journal Of The British Sociological Association, 12, 27-49.

Gleasure, R. (2015). Resistance to crowdfunding among entrepreneurs: An impression management perspective. The Journal of Strategic Information Systems, 24(4), 219-233.

Goodhue, D. L., \& Thompson, R. L. (1995). Task-technology fit and individual performance. MIS Quarterly. 213-236.

Gurman, T. A., Rubin, S. E., \& Roess, A. A. (2012). Effectiveness of mHealth behavior change communication interventions in developing countries: a systematic review of the literature. Journal of Health Communication. 17(sup1), 82-104.

Hackbarth, G., Grover, V., \& Mun, Y. Y. (2003). Computer playfulness and anxiety: positive and negative mediators of the system experience effect on perceived ease of use. Information \& Management. 40(3), 221-232.

Hacking, D., Haricharan, H. J., Brittain, K., Lau, Y. K., Cassidy, T., \& Heap, M. (2016). Hypertension health promotion via text messaging at a community health center in South Africa: a mixed methods study. JMIR mHealth and uHealth, 4(1).

Hareli, S., \& Hess, U. (2010). What emotional reactions can tell us about the nature of others: An appraisal perspective on person perception. Cognition and Emotion, 24(1), 128-140.

Heeks, R. (2006). Health information systems: Failure, success and improvisation. International Journal of Medical Informatics. 75(2), 125-137. 
Higgs, E. S., Goldberg, A. B., Labrique, A. B., Cook, S. H., Schmid, C., Cole, C. F., \& Obregón, R. A. (2014). Understanding the role of mHealth and other media interventions for behavior change to enhance child survival and development in low-and middle-income countries: an evidence review. Journal of Health Communication. 19(sup1), 164-189.

Hufnagel, H. (2012). Compendium 2012: Innovative Health Technologies for Low Resource Settings. Paper presented at the 13th World Congress on Public Health (April 23-27, 2012).

Im, I., Hong, S., \& Kang, M. S. (2011). An international comparison of technology adoption: Testing the UTAUT model. Information $\mathcal{E}$ Management. Information $\mathcal{E}$ management, 48(1), $1-8$.

Jahoda, G. (2012). Critical reflections on some recent definitions of "culture". Culture $\mathcal{E}$ Psychology, 18(3), 289-303.

Jensen, T., \& Vatrapu, R. (2015). Ships \& Roses: A Revelatory Case Study of Affordances in International Trade. Paper presented at the European Conference on Information Systems.

Johnston, A. C., Warkentin, M., McBride, M., \& Carter, L. (2016). Dispositional and situational factors: influences on information security policy violations. European Journal of Information Systems, 25(3), 231-251.

Kabuya, C., Wright, G., Odama, A., \& O'Mahoney, D. (2014). Routine data for disease surveillance in the undeveloped region of the OR Tambo district of the Eastern Cape Province. Stud Health Technol Inform, 197, 103-107.

Kahn, J. G., Yang, J. S., \& Kahn, J. S. (2010). 'Mobile'health needs and opportunities in developing countries. Health Affairs, 29(2), 252-258.

Kay, M., Santos, J., \& Takane, M. (2011). mHealth: New horizons for health through mobile technologies. World Health Organization, 64(7), 66-71.

Kim, G., Shin, B., \& Lee, H. G. (2009). Understanding dynamics between initial trust and usage intentions of mobile banking. Information Systems Journal, 19(3), 283-311.

Knoble, S. J., \& Bhusal, M. R. (2015). Electronic Diagnostic Algorithms to Assist Mid-level Health Care Workers in Nepal: A mixed-method exploratory study. International Journal of Medical Informatics. 334-340.

Knoke, D. (1994). Networks of elite structure and decision making. Sage Focus Editions, 171, 274-274.

Krohne, H. W. (2002). Stress and coping theories. International Encyclopedia of the Social Behavioral Sceinces, 22, 15163-15170.

Kuo, B. C. (2011). Culture's consequences on coping: Theories, evidences, and dimensionalities. Journal of Cross-Cultural Psychology, 42(6), 1084-1100.

Lazarus, R. S., \& Folkman, S. (1984). Stress, appraisal, and coping: Springer Publishing Company.

Lazarus, R. S., \& Folkman, S. (1987). Transactional theory and research on emotions and coping. European Journal of Personality. 1(3), 141-169.

Lee, H. Y., Qu, H., \& Kim, Y. S. (2007). A study of the impact of personal innovativeness on online travel shopping behavior-A case study of Korean travelers. Tourism Management, 28(3), 886-897. 
Lee, J.-N., Huynh, M. Q., \& Hirschheim, R. (2008). An integrative model of trust on IT outsourcing: Examining a bilateral perspective. Information Systems Frontiers, 10(2), 145163.

Leon, N., Schneider, H., \& Daviaud, E. (2012). Applying a framework for assessing the health system challenges to scaling up mHealth in South Africa. BMC Medical Informatics and Decision Making. 12(1), 123.

Lewis, W., Agarwal, R., \& Sambamurthy, V. (2003). Sources of influence on beliefs about information technology use: An empirical study of knowledge workers. MIS Quarterly. 657-678.

Liang, H., \& Xue, Y. (2009). Avoidance of information technology threats: a theoretical perspective. MIS Quarterly 71-90.

Lim, K. H., Benbasat, I., \& Ward, L. M. (2000). The role of multimedia in changing first impression bias. Information Systems Research, 11(2), 115-136.

Lowe, A. (1996). An explanation of grounded theory: [Helsinki]: Swedish School of Economics and Business Administration.

Lyon, B. L. (2000). Stress, coping, and health. Handbook of Stress, Coping and Health: Implications for Nursing Research, Theory, and Practice. 3-23.

Maeder, A. (2014). Evaluating success of mobile health projects in the developing world. obal $T, 7$.

Maier, C., Laumer, S., Weinert, C., \& Weitzel, T. (2015). The effects of technostress and switching stress on discontinued use of social networking services: a study of Facebook use. Information Systems Journal, 25(3), 275-308.

Malvey, D., \& Slovensky, D. J. (2014). mHealth: transforming healthcare: Springer.

Mathieson, K. (1991). Predicting user intentions: comparing the technology acceptance model with the theory of planned behavior. Information Systems Research, 2(3), 173-191.

Mavhu, W., Willis, N., Mufuka, J., Mangenah, C., Mvududu, K., Bernays, S., . . Weiss, H. A. (2017). Evaluating a multi-component, community-based program to improve adherence and retention in care among adolescents living with HIV in Zimbabwe: study protocol for a cluster randomized controlled trial. Trials, 18(1), 478.

Mechael, P. (2009). The case for mHealth in developing countries. Innovations. 4(1), 103-118.

Medhanyie, A., Spigt, M., Dinant, G., \& Blanco, R. (2012). Knowledge and performance of the Ethiopian health extension workers on antenatal and delivery care: a cross-sectional study. Human Resources For Health. 10(1), 44.

Medhanyie, A. A., Moser, A., Spigt, M., Yebyo, H., Little, A., Dinant, G., \& Blanco, R. (2015). Mobile health data collection at primary health care in Ethiopia: a feasible challenge. Journal of Clinical Epidemiology. 68(1), 80-86.

Miah, S. J., Hasan, N., Hasan, R., \& Gammack, J. (2017). Healthcare support for underserved communities using a mobile social media platform. Information Systems, 66, 1-12.

Miles, M. B., \& Huberman, A. M. (1994). Qualitative data analysis: An expanded sourcebook: sage. 
Miller, C. T., \& Kaiser, C. R. (2001). A theoretical perspective on coping with stigma. Journal of Social Issues 57(1), 73-92.

Modi, D., Gopalan, R., Shah, S., Venkatraman, S., Desai, G., Desai, S., \& Shah, P. (2015). Development and formative evaluation of an innovative mHealth intervention for improving coverage of community-based maternal, newborn and child health services in rural areas of India. Global Health Action. 8(1), 26769.

Moreland, J., French, T., \& Cumming, G. (2016). Exploring online health information seeking in Scotland. Paper presented at the Proceedings of the 3rd European Workshop on Practical Aspects of Health Informatics. Elgin, UK. Retrieved from http://radar.gsa.ac.uk/4582/1/Exploring\% 20OHIS\% 20Scotland. pdf.

Morrison, J., Shrestha, N. R., Hayes, B., \& Zimmerman, M. (2013). Mobile phone support for rural health workers in Nepal through 'celemedicine'. Journal of Nepal Medical Association, 52(191).

Murray, E., Lo, B., Pollack, L., Donelan, K., Catania, J., Lee, K., . . Turner, R. (2003). The impact of health information on the Internet on health care and the physician-patient relationship: national US survey among 1.050 US physicians. J Med Internet Res, 5(3), e17.

Nach, H., \& Lejeune, A. (2010). Coping with information technology challenges to identity: A theoretical framework. Computers in Human Behavior, 26(4), 618-629.

Newton, A. T., \& McIntosh, D. N. (2010). Specific religious beliefs in a cognitive appraisal model of stress and coping. International Journal for the Psychology of Religion, 20(1), 39-58.

Ngabo, F., Nguimfack, J., Nwaigwe, F., Mugeni, C., Muhoza, D., Wilson, D. R., . . Binagwaho, A. (2012). Designing and implementing an innovative SMS-based alert system (RapidSMS-MCH) to monitor pregnancy and reduce maternal and child deaths in Rwanda. The Pan African Medical Journal, 13, 1-15.

Nhavoto, J. A., Grönlund, Å., \& Klein, G. O. (2017). Mobile health treatment support intervention for HIV and tuberculosis in Mozambique: Perspectives of patients and healthcare workers. PloS One. 12(4), e0176051.

Nicolaou, A. I., \& McKnight, D. H. (2006). Perceived information quality in data exchanges: Effects on risk, trust, and intention to use. Information Systems Research, 17(4), 332-351.

Orlikowski, W. J. (1993). CASE tools as organizational change: Investigating incremental and radical changes in systems development. MIS Quarterly. 309-340.

Paina, L., \& Peters, D. H. (2011). Understanding pathways for scaling up health services through the lens of complex adaptive systems. Health Policy and Planning. 27(5), 365-373.

Paradis, J. (2011). Individual differences in child English second language acquisition: Comparing child-internal and child-external factors. Linguistic approaches to bilingualism, 1(3), 213-237.

Patton, M. Q. (1990). Qualitative evaluation and research methods: SAGE Publications, inc, Berverly Hills, CA. 
Polites, G. L. (2005). Counterintentional habit as an inhibitor of technology acceptance. Paper presented at the Proceedings of the 2005 Southern Association for Information Systems Conference, 264-271.

Ragu-Nathan, T., Tarafdar, M., Ragu-Nathan, B. S., \& Tu, Q. (2008). The consequences of technostress for end users in organizations: Conceptual development and empirical validation. Information Systems Research, 19(4), 417-433.

Ram, S., \& Khatri, V. (2005). A comprehensive framework for modeling set-based business rules during conceptual database design. Information Systems, 30(2), 89-118.

Recker, J. C. (2014). Towards a theory of individual-level discontinuance of information systems use. Paper presented at the Proceedings of the 35th International Conference on Information Systems.

Reinecke, K., Yeh, T., Miratrix, L., Mardiko, R., Zhao, Y., Liu, J., \& Gajos, K. Z. (2013). Predicting users' first impressions of website aesthetics with a quantification of perceived visual complexity and colorfulness. Paper presented at the SIGCHI Conference on Human Factors in Computing Systems.

Roberts, P., Priest, H., \& Traynor, M. (2006). Reliability and validity in research. Nursing Standard. 20(44), 41-45.

Rogers, E. M. (2003). Elements of diffusion. Diffusion of Innovations, . 5, 1-38.

Sanner, T. A., Manda, T. D., \& Nielsen, P. (2014). Grafting: Balancing Control and Cultivation in Information Infrastructure Innovation. Journal of the Association for Information Systems, 15(4), 220-243.

Sarker, S., Sarker, S., Sahaym, A., \& Bjørn-Andersen, N. (2012). Exploring Value Cocreation in Relationships Between an ERP Vendor and its Partners: A Revelatory Case Study. MIS Quarterly. 36(1).

Seidel, S., \& Urquhart, C. (2013). On emergence and forcing in information systems grounded theory studies: The case of Strauss and Corbin. Journal of Information Technology, 28(3), 237-260.

Shu, Q., Tu, Q., \& Wang, K. (2011). The impact of computer self-efficacy and technology dependence on computer-related technostress: A social cognitive theory perspective. International Journal of Human-Computer Interaction, 27(10), 923-939.

Simon, S. K., \& Seldon, H. L. (2012). Personal health records: Mobile biosensors and smartphones for developing countries. Studies in Health Technology and Informatics 182, 125-132.

Srite, M., \& Karahanna, E. (2006). The role of espoused national cultural values in technology acceptance. MIS Quarterly. 679-704.

Stanton, M. C., Mkwanda, S. Z., Debrah, A. Y., Batsa, L., Biritwum, N.-K., Hoerauf, A., . . . Kelly-Hope, L. A. (2015). Developing a community-led SMS reporting tool for the rapid assessment of lymphatic filariasis morbidity burden: case studies from Malawi and Ghana. BMC Infectious Diseases 15(1), 214.

Strauss, A., \& Corbin, J. (1998). Basics of qualitative research: Procedures and techniques for developing grounded theory: Thousand Oaks, CA: Sage. 
Taylor, S., \& Todd, P. A. (1995). Understanding information technology usage: A test of competing models. Information Systems Research, 6(2), 144-176.

Terry, D. J. (1994). Determinants of coping: The role of stable and situational factors. Journal of Personality and Social Psychology. 66(5), 895.

Urquhart, C. (2000). An encounter with grounded theory: Tackling the practical and philosophical issues. Qualitative Research in IS: Issues and Trends. 104-140.

Urquhart, C., Lehmann, H., \& Myers, M. D. (2010). Putting the 'theory'back into grounded theory: guidelines for grounded theory studies in information systems. Information Systems Journal, 20(4), 357-381.

Venkatesh, V. (2000). Determinants of perceived ease of use: Integrating perceived behavioral control, computer anxiety and enjoyment into the technology acceptance model. Information Systems Research, 11(4), 342-365.

Venkatesh, V., \& Morris, M. G. (2000). Why don't men ever stop to ask for directions? Gender, social influence, and their role in technology acceptance and usage behavior. MIS Quarterly. 115-139.

Venkatesh, V., Morris, M. G., Davis, G. B., \& Davis, F. D. (2003). User acceptance of information technology: Toward a unified view. MIS Quarterly. 425-478.

Venkatesh, V., Thong, J. Y., \& Xu, X. (2012). Consumer acceptance and use of information technology: extending the unified theory of acceptance and use of technology. MIS Quarterly. 157-178.

Wedgwood, R. (2006). The internal and external components of cognition. Contemporary Debates in Cognitive Science. 307-325.

Wisniewski, P., Xu, H., \& Chen, Y. (2014). Understanding user adaptation strategies for the launching of facebook timeline. Paper presented at the Proceedings of the 32nd annual ACM Conference on Human Factors in Computing Systems.

Xue, Y., Liang, H., Mbarika, V., Hauser, R., Schwager, P., \& Getahun, M. K. (2015). Investigating the resistance to telemedicine in Ethiopia. International Journal of Medical Informatics. 84(8), 537-547.

Yin, R. K. (2013). Case study research design and methods third edition. Applied Social Research Methods Series. 5, 1-312. 


\section{Appendix A - Data sources and interviewees' roles}

\begin{tabular}{|c|c|}
\hline Data sources & Role \\
\hline $\begin{array}{l}8^{*} \quad \text { interviews with } \\
\text { seven } \\
\text { Parents/Guardians } \\
\text { (PGs) }\end{array}$ & $\begin{array}{l}\text { Mothers - these are parents to the children under the age of five in the target } \\
\text { community whose primary tasks amongst others is to take care of their children's } \\
\text { health in their homes. }\end{array}$ \\
\hline $\begin{array}{l}8^{*} \quad \text { interviews with } \\
\text { seven Rural Healthcare } \\
\text { Workers (RHCWs) }\end{array}$ & $\begin{array}{l}\text { RHCWs - these are trained healthcare professionals working in the community } \\
\text { health centres. RHCWs are the lowest cadre of health professional in the health } \\
\text { system. They are a mixture of nurses and those trained specifically to help in } \\
\text { healthcare services. RCHWs are called community healthcare workers (e.g. DeRenzi } \\
\text { et al., 2012), health extension workers (e.g. A. Medhanyie, Spigt, Dinant, \& Blanco, } \\
\text { 2012), and local health workers (e.g. Ngabo et al., 2012) in other jurisdictions. } \\
\text { RHCWs were the direct users of the mHealth tool in this study. }\end{array}$ \\
\hline \multirow[t]{6}{*}{$\begin{array}{l}8^{*} \text { interviews with six } \\
\text { Facilitators }\end{array}$} & $\begin{array}{l}\text { Head of Service - Head of the entire public service or public servants that work in } \\
\text { Enugu State civil service. Responsibility include to make sure that all adapt } \\
\text { appropriately in their workplace and working in order that they deliver on their } \\
\text { mandate. }\end{array}$ \\
\hline & $\begin{array}{l}\text { Local Government Chairman - Chairman of the transitional committee of Nsukka } \\
\text { Local Government. One of the } 17 \text { local governments in Enugu State. }\end{array}$ \\
\hline & $\begin{array}{l}\text { Health Data Manager }- \text { Head, Enugu State's Health Management System Officer. } \\
\text { Work responsibility include, human resource officer, health information system } \\
\text { officer and in-charge of the health accounts of the State. }\end{array}$ \\
\hline & $\begin{array}{l}\text { Provost of College of Medicine - Responsibilities include, train medical students, } \\
\text { and support them through their medical training. }\end{array}$ \\
\hline & $\begin{array}{l}\text { Director Clinical Services - Facilitation of service delivery by all the clinical staff, } \\
\text { the Doctors, the Nurses, the Medical Laboratory Scientists, the Pharmacies, the } \\
\text { Therapists and all the other Medical or Healthcare Workers. }\end{array}$ \\
\hline & $\begin{array}{l}\text { Director, Primary Health Care (Local Government Services Commission)- Work } \\
\text { responsibilities include the facilitation of national programmes at the local } \\
\text { government levels. }\end{array}$ \\
\hline \multirow{6}{*}{$\begin{array}{l}8^{*} \text { interviews with six } \\
\text { Dev } 8^{*} \text { interviews } \\
\text { with six System } \\
\text { Developers }\end{array}$} & $\begin{array}{l}\text { Principal Investigator - the head of the IMPACT project. Lead the designing the } \\
\text { app, and decides on what the app ultimately becomes. }\end{array}$ \\
\hline & $\begin{array}{l}\text { Software Programmer - Involves mainly in software development, software } \\
\text { design, and user interface design, and usability analysis. }\end{array}$ \\
\hline & $\begin{array}{l}\text { Research Partner - lead collaborator representing IMPACT project. Makes } \\
\text { contribution towards the designing and customising the app. }\end{array}$ \\
\hline & $\begin{array}{l}\text { Research Collaborator-Offers advice on the clinical aspects of the app design and } \\
\text { development. }\end{array}$ \\
\hline & $\begin{array}{l}\text { Member of the Collaborator's Team - Former Director of Disease Control in the } \\
\text { State's Health Ministry. Insights on challenges during guidelines developments. }\end{array}$ \\
\hline & $\begin{array}{l}\text { Former Director of Public and Primary Healthcare at the National level. } \\
\text { Participated in writing the health policy and the health guidelines. }\end{array}$ \\
\hline Field Notes From & $\begin{array}{l}\text { Observations of PGs' homes, Edem-Ani, Alor-Unor, Ibagwa-Ani, Okpuje, and } \\
\text { Okwutu health centres. }\end{array}$ \\
\hline $\begin{array}{l}\text { Medical papers \& } \\
\text { Photographs }\end{array}$ & $\begin{array}{l}\text { Images of rural health centres, some pictures of the social actors, the paper-based } \\
\text { Standing Operation Procedure (SOP); paper-based facility registers, paper-based } \\
\text { summary form, wall photographs of Health Information Systems (HIS) related } \\
\text { charts, graphs and paper forms. }\end{array}$ \\
\hline
\end{tabular}




\section{Appendix B - Research questions for Rural Healthcare Workers (RHCWs)}

How do you feel about this new mHealth app?

To what extent do you think that this new app would have a positive impact on your work practices?

To what extent do you think that this new app would have a positive impact on co-workers' work practices?

To what extent do you think that this new app would have a negative impact on your work practices?

To what extent do you think that this new app would have a negative impact on co-workers' work practices?

To what extent do you believe this new app would be part of a broader positive/negative trend in healthcare delivery in Enugu State?

To what extent do you intend to explore different features on this new app?

What, if any, other things do you think this new app could do for you?

What, if any, challenges did you face connecting to the internet?

To what extent do you see this new app changing the way you perform your duties?

To what extent do you think you can perform your duties using this new app without outside help?

What, if any, challenges did you face when trying to get familiar using this new app?

Is there any reason why you would avoid using this new app in the future?

How do you feel after using this new mHealth app?

After using this new app, to what extent do you think that it would have a positive impact on your work practices?

After using this new app, to what extent do you think that it would have a positive impact on co-workers' work practices?

After using this new app, to what extent do you think that it would have a negative impact on your work practices?

After using this new app, to what extent do you think that this new app would have a negative impact on co-workers' work practice?

After using this new app, to what extent do you believe it would be part of a broader positive/negative trend in healthcare delivery in Enugu State? 


\section{Appendix C - Research questions for Parents/Guardians (PGs)}

How do you feel about this new mHealth app?

To what extent do you think that this new app would have a positive impact on the way your child would be assessed at the health centre?

To what extent do you think that this new app would have a positive impact on fellow parents in your community?

To what extent do you think that this new app would have a negative impact on fellow parents in your community?

To what extent do you think that this new app would have a negative impact on fellow parents in your community?

To what extent do you believe this new app would be part of a broader positive/negative trend in healthcare delivery in Enugu State?

To what extent do you think that healthcare workers would like to explore the different features on this new app?

What, if any, other things do you think this new app could do for rural healthcare workers?

What, if any, challenges do you think that rural healthcare workers would face connecting to the internet?

To what extent do you see this new app changing the way rural healthcare workers perform their duties?

To what extent do you think that healthcare workers can perform their duties using this new app without outside help?

What, if any, challenges do you think that rural healthcare workers would face when trying to get familiar with using this new app?

Is there any reason why you think that rural healthcare workers would avoid using this new app in the future?

How do you feel after using this new mHealth app?

After using this new app, to what extent do you think that it would have a positive impact on healthcare practices in Enugu State?

After using this new app, to what extent do you think that it would have a positive impact on rural healthcare workers ' practices?

After using this new app, to what extent do you think that it would have a negative impact on health practices in Enugu State?

After using this new app, to what extent do you think that this new app would have a negative impact on rural healthcare workers' practices?

After using this new app on your child/children, to what extent do you believe it would be part of a broader positive/negative trend in healthcare delivery in Enugu State? 


\section{Appendix D - Research questions for Facilitators}

How do you feel about this new mHealth app?

To what extent do you think that this new app would have a positive impact on the way you want children to be assessed in Enugu State?

To what extent do you think that this new app would have a positive impact on fellow facilitators in Enugu healthcare system?

To what extent do you think that this new app would have a negative impact on fellow facilitators in Enugu healthcare system?

To what extent do you think that this new app would have a negative impact on fellow facilitators in Enugu healthcare system?

To what extent do you believe this new app would be part of a broader positive/negative trend in healthcare delivery in Enugu State?

To what extent do you think that rural healthcare workers would like to explore the different features on this new app?

What, if any, other things do you think this new app could do for rural healthcare workers?

What, if any, challenges do you think that rural healthcare workers would face connecting to the internet?

To what extent do you see this new app changing the way rural healthcare workers perform their duties?

To what extent do you think that rural healthcare workers can perform their duties using this new app without outside help?

What, if any, challenges do you think that rural healthcare workers would face when trying to get familiar with using this new app?

Is there any reason why you think that rural healthcare workers would avoid using this new app in the future?

How do you feel after using this new mHealth app?

After using this new app, to what extent do you think that it would have a positive impact on healthcare practices in Enugu State?

After using this new app, to what extent do you think that it would have a positive impact on healthcare workers' practices?

After using this new app, to what extent do you think that it would have a negative impact on health practices in Enugu State?

After using this new app, to what extent do you think that this new app would have a negative impact healthcare workers' practices?

After using this new app, to what extent do you believe it would be part of a broader positive/negative trend in healthcare delivery in Enugu State? 


\section{Appendix E - Research questions for Developers}

How do you feel about this new mHealth app?

To what extent do you think that this new app would have a positive impact on the way you want children to be assessed in Enugu State?

To what extent do you think that this new app would have a positive impact on fellow developers in Enugu healthcare system?

To what extent do you think that this new app would have a negative impact on fellow developers in Enugu healthcare system?

To what extent do you think that this new app would have a negative impact on fellow developers in Enugu healthcare system?

To what extent do you believe this new app would be part of a broader positive/negative trend in healthcare delivery in Enugu State?

To what extent do you think that rural healthcare workers would like to explore the different features on this new app?

What, if any, other things do you think this new app could do for rural healthcare workers in Enugu State?

What, if any, challenges do you think that rural healthcare workers would face connecting to the internet?

To what extent do you see this new app changing the way healthcare workers perform their duties?

To what extent do you think that rural healthcare workers can perform their duties using this new app without outside help?

What, if any, challenges do you think that rural healthcare workers would face when trying to get familiar with using this new app?

Is there any reason why you think that rural healthcare workers would avoid using this new app in the future?

How do you feel after using this new mHealth app?

After using this new app, to what extent do you think that it would have a positive impact on healthcare practices in Enugu State?

After using this new app, to what extent do you think that it would have a positive impact on rural healthcare workers' practices?

After using this new app, to what extent do you think that it would have a negative impact on health practices in Enugu State?

After using this new app, to what extent do you think that this new app would have a negative impact rural healthcare workers' practices?

After using this new app, to what extent do you believe it would be part of a broader positive/negative trend in healthcare delivery in Enugu State? 


\section{Appendix F - Details of open, axial, and selective coding}

The GT coding process included three major types of coding, namely: through open, axial, and selective coding processes (Orlikowski, 1993; Urquhart, Lehmann, \& Myers, 2010).

\section{F1 - Open Coding}

Open coding refers to classifying/breaking data into concepts that may explain important incidences or happenings about the phenomenon (Böhm, 2004; Gasson, 2004). In order to stay deeply connected to the research topic we followed the line of questioning provided by Glazer (1978, p. 57) that is used in generating codes: 1) "What is this data a study of?" 2) "What category does this incident indicate?" 3) "What is actually happening in the data?" Open coding began with a 'line-by-line' analysis of the data (Charmaz, 2006, 2014). Through this process, we created 35 codes that were given conceptual labels that related to 450 word-based data-sets from thirty-two interviews along with written notes (30 pages) from the interviews, and documentation. Subsequently, conceptually similar incidences were grouped together to form common categories (Corbin \& Strauss, 1990). In open coding, we focused on the stakeholders' primary appraisal of the proposed mHealth tool for healthcare delivery in Enugu State. For example, we coded a portion of RHCWs' interview, i.e., "many people find it difficult to change the way they do things" as 'Habit', and a portion of Facilitators' interview, i.e., "the people who are not good with technology will be afraid of its introduction" as 'computer anxiety'. Open codes were developed for each portion of the data-set as presented in Tables 2 and 3. Emerging codes from each data-set were subsequently compared against varying viewpoints as recurring themes emerge from the data for consistency.

\section{F2 - Axial Coding}

Axial coding refers to the comparisons of the emerging themes or subthemes to classify them into meaningful categories which enable the creation of a more hierarchical groupings (Abraham, Boudreau, Junglas, \& Watson, 2013; Gasson, 2004). That is, it helps to fine-tune and differentiate themes or subthemes and lends them into other status or levels of classifications in relation to the data. Axial coding entails the search for relationships between coded concepts identified during open coding and by ensuring that the evolving interview instruments captured emerging constructs and relationships (Gasson, 2004; Gleasure, 2015). The iterations between the researchers and the data allowed the initial model to be expanded and delineated into a clearly defined and well-articulated hypothesis-based model and the underlining processes. Following this technique, we related and combined codes to form themes representing sources of threat and opportunity appraisals towards mHealth assimilation. These themes fall under the 'causal conditions' category of Strauss and Corbin paradigm (Bohm, 2004; Seidel \& Urquhart, 2013). For example, we created relationship between the codes of 'habit', 'computer anxiety' and the effect of norms and cultural values to form the theme 'Perceived threat from process uncertainty'.

\section{F3 - Theoretical memos}

Theoretical memos are write-ups of ideas relating to codes and themes, and between themes themselves which ultimately form the basis for writing theory (Bohm, 2004; Gasson, 2004). Memos provide avenues to capture insights into the analysis process and contain clues to integration in so far as the researchers have systematically recognised the properties of the ideas together with their dimensions (Strauss \& Corbin, 1998). For example, the memo 'The inadvertent threat perceived by stakeholders with regards to changes that would affect habit/practice.' refers to the proposed introduction of an mHealth tool. For it to be 'positively' appraised by the target communities, the programme initiators need to design technological solutions that reflect local realities and needs (Chib, 2013; Kay, Santos, \& Takane, 2011). 
Omitting memos and moving directly from coding to writing-up may impact the conceptual detail and integration of ideas (Corbin \& Strauss, 1990; Glaser \& Strauss, 1967). Constructs and relationships identified in theoretical memos must be supported by further data analysis or it would just speculation and not theory (Gasson, 2004).

\section{F4 - Selective coding}

Selective coding is the integrating and refining of emerging core categories at the later stages of a coding process (Corbin \& Strauss, 1990, 2008, 2014). This integrative procedural feature is considered an essential force in theory building or in explaining phenomenon (Seidel \& Urquhart, 2013; Urquhart, 2000). The refining process involves constant comparison between categories and data (Lowe, 1996). That is, moving up and down the levels of analysis and looking for traces of relationships which it might explain and by incorporating relevant data up to a point where no more evidence is discovered (data saturation) (Andriopoulos \& Lowe, 2000). It was at this stage that poorly developed categories were discovered and refined by revisiting data to fill-in the gaps. Subsequently, core categories were defined and labelled. Two core categories resulting from axial coding were consistent with the classification that evolved from contemporary scholars' work in primary appraisals of technology application in organisations setting: 'Threats' and 'Opportunities' (Connolly \& Bhattacherjee, 2011; Wisniewski et al., 2014).

Copyright: (c) 2019 Eze, Gleasure \& Heavin. This is an open-access article distributed under the terms of the Creative Commons Attribution-NonCommercial 3.0 Australia License, which permits non-commercial use, distribution, and reproduction in any medium, provided the original author and AJIS are credited.

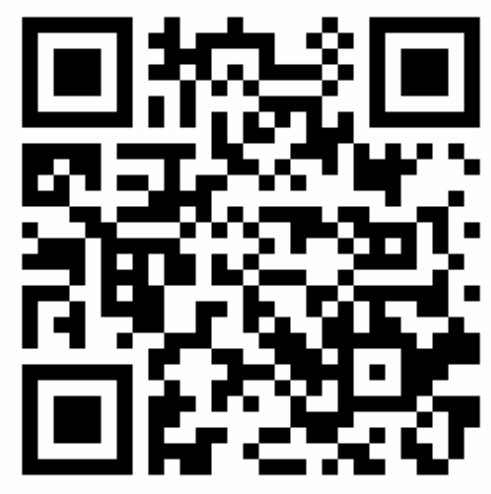

